\title{
STUDI BANDING PERFORMA TIANG UTAMA BUS UNTUK MODEL TUNGGAL DAN MODEL GANDA DENGAN MENGGUNAKAN SIMULASI METODA ELEMEN HINGGA
}

\author{
Budi Setiyana \\ Departemen Teknik Mesin Fakultas Teknik Universitas Diponegoro \\ Jl. Prof. Sudharto, SH Kampus Tembalang, Semarang \\ Email: bsetiyana@yahoo.com
}

\begin{abstract}
ABSTRAK
Sehingga setiap komponen dari bus harus memiliki struktur rangka yang kuat terutama pada tiang utama. Masing-masing tiang utama umumnya dibuat dari sebuah baja profil tunggal (model tunggal). Tetapi tiang utama bus ini juga dapat dibuat dari gabungan dua buah baja profil dengan cara di las (model ganda) yang mempunyai dimensi luar yang sama dengan model tunggal. Penelitian ini bertujuan memodelkan dan membandingkan performa tiang utama sebuah bus untuk tiang model tunggal dan model ganda dengan menggunakan FEM (Finite Element Method). Hasil simulasi FEM adalah berupa tegangan dan displacement. Berdasarkan hasil analisis, didapatkan tegangan dan displacement pada tiang utama model tunggal yaitu berturut turut sebesar $1,287 \times 10^{6} \mathrm{~N} / \mathrm{m}^{2}$ dan $6,448 \times 10^{-1} \mathrm{~mm}$. Sedangkan tegangan dan displacement pada tiang utama model ganda yaitu berturut turut sebesar 2,936 $x$ $10^{6} \mathrm{~N} / \mathrm{m}^{2}$ dan $1,580 \mathrm{~mm}$. Dari hasil simulasi, bentuk rangka tiang utama yang terbaik adalah tiang utama model tunggal karena memiliki tingat keamanan yang tinggi dibandingkan dengan tiang model ganda baik dari sisi tegangan maupun displacement.
\end{abstract}

Kata kunci: FEM, model tunggal, model ganda, tiang utama

\section{PENDAHULUAN}

Rangka rangka bus adalah suatu bagian dari bus yang membentuk bus secara umum. Rangka bus sangat mempengaruhi kestabilan bus dalam beroperasi dan mempunyai peranan terhadap keamanan penumpang yang penting bila pada saat terjadi benturan keras. Bagian ini juga merupakan tempat menenpelnya body bus, kaca dan bagian interior pada bus.

Dalam proses perakitan bus, rangka dikelompokkan menjadi 5 bagian, yaitu:

1. Rangka bagian lantai

Rangka bagian ini merupakan bagian rangka yang menempel dengan chassis. Rangka ini merupakan tempat menempelnya bagian lantai, tempat duduk, dsb. Oleh karena itu, bagian ini merupaka bagian rangka yang paling bayak menahan beban kendaraan. Bagian ini menopang rangka bagian samping, depan dan belakang secara langsung.

2. Rangka bagian samping

Rangka bagian samping merupakan rangka yang memberi bentuk tegak dan memanjang searah dengan panjang bus, merupakan tempat menempelnya pintu, body dan kaca. Dibagian ini terdapat tiang utama bus. Secara umum rangka bagian samping kanan dan kiri pada struktur bus mempunyai bentuk dan penampang yang sama, kecuali pada bagian pintu.
3. Rangka bagian atap

Merupakan struktur rangka bagian atas yang menutupi bus. Di rangka bagian atap menempel bagian bus seperti body, plafon dan $A C$. Rangka ini ditopang oleh rangka bagian samping, depan dan belakang secara langsung.

4. Rangka bagian depan

Rangka bagian depan merupakan bagian yang paling berpengaruh ketika terjadi tabrakan dari arah depan, sekaligus tempat menempelnya bumper yang berfungsi untuk meredam tabrakan.

5. Rangka bagian belakang

Rangka bagian belakang mempunyai fungsi yang hampir sama dengan rangka bagian depan, selain itu bagian ini juga memberikan bentuk visual bus ketika dilihat dari arah belakang.

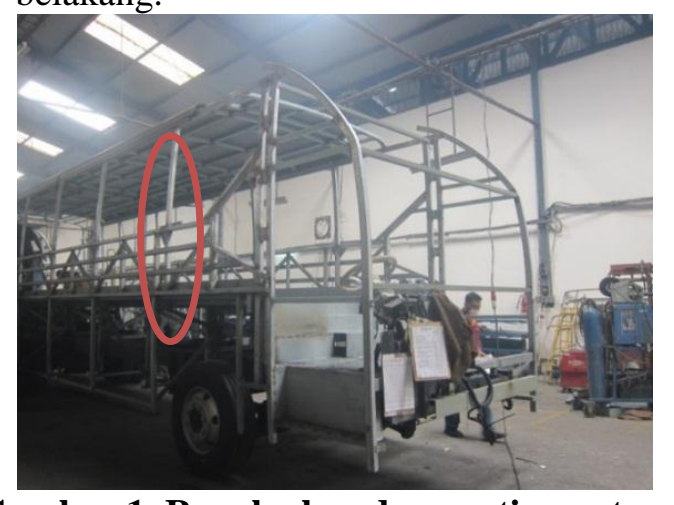

Gambar 1. Rangka bus dengan tiang utama 
Tiang utama umumnya dibuat dari sebuah baja profil tunggal (model tunggal). Tetapi tiang utama bus ini juga dapat dibuat dari gabungan dua buah baja profil dengan cara di las (model ganda) yang mempunyai dimensi luar yang sama dengan model tunggal. Penelitian ini bertujuan memodelkan dan membandingkan performa tiang utama sebuah bus untuk tiang model tunggal dan model ganda dengan menggunakan FEM (Finite Element Method). Performa yang dianalisis berupa tegangan dan displacement yang terjadi saat tiang tersebut mendapat beban dari berat atap.

\section{METODA PENELITIAN \\ Bahan}

Panjang tiang utama model tunggal yang berbentuk pipa hollow yaitu dengan panjang $2880 \mathrm{~mm}$ dengan tebal $3 \mathrm{~mm}$. Panjang dan lebar tampak depan pipa yaitu $60 \times 40 \mathrm{~mm}$. Dimensi pada benda kerja akan sesuai dengan gambar 2 dibawah ini.

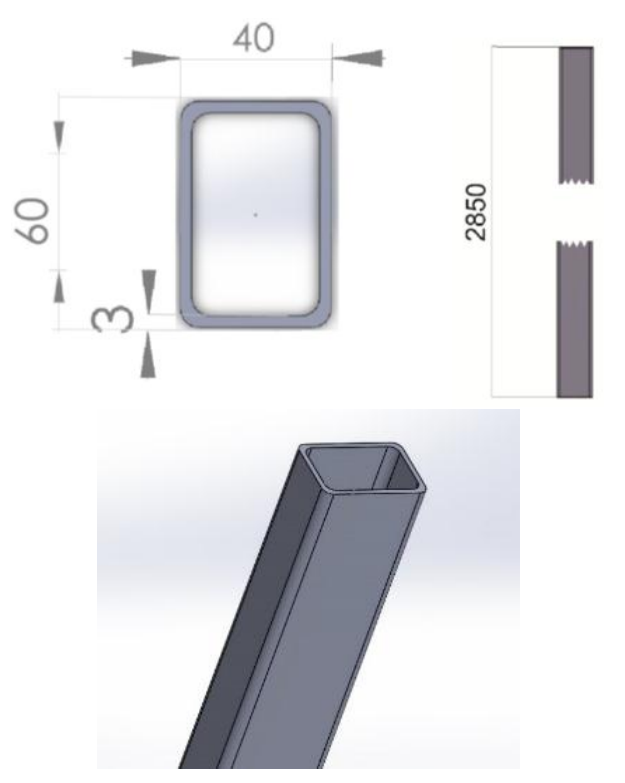

\section{Gambar 2. Tampilan proyeksi dan perspektif tiang utama bus model tunggal}

Tiang utama model ganda adalah gabungan dari pipa hollow dengan panjang $2880 \mathrm{~mm}$ dan tebal $3 \mathrm{~mm}$. Panjang dan lebar tampak depan pipa yaitu 30 x $40 \mathrm{~mm}$. Dimensi pada benda kerja akan sesuai dengan gambar 3 dibawah ini.

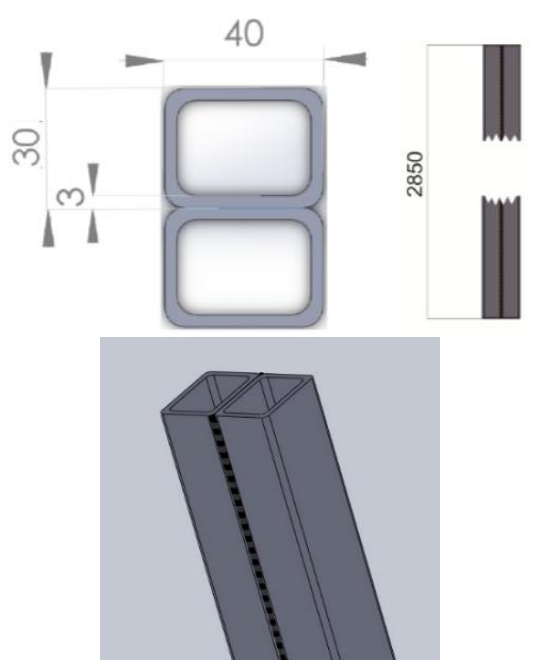

Gambar 3. Tampilan proyeksi dan perspektif tiang utama bus model ganda.

Jenis material tiang utama bus yang gunakan sebagai acuan untuk analisis disini yaitu STKM 18A atau JIS G 3445 Grade 18A. Data dari material STKM 18A dapat dilihat pada tabel 1.

Tabel 1. Data material STKM 18A

\begin{tabular}{|c|c|}
\hline \multicolumn{2}{|c|}{ STRUCTURAL STEEL } \\
\hline Elastic Modulus $\left(\mathrm{N} / \mathrm{m}^{2}\right)$ & $2 e+011$ \\
\hline Poison's Ratio & 0.29 \\
\hline Mass Density $\left(\mathrm{Kg} / \mathrm{m}^{3}\right)$ & 7870 \\
\hline Tensile Strength $(\mathrm{MPa})$ & 440 \\
\hline Yield Strength $(\mathrm{MPa})$ & 275 \\
\hline
\end{tabular}

\section{Pemodelan dengan Metode Elemen Hingga}

Metode Elemen Hingga adalah salah satu metode numerik yang digunakan untuk menyelesaikan permasalahan teknik dengan persamaan diferensial ataupun teori energi. FEM membagi sebuah struktur menjadi beberapa elemen (potongan struktur). Dalam menganalisa struktur pengelasan pada bus, penulis menggunakan software bantu "SolidWorks" untuk memodelkan struktur dan menganalisis tiang utama bus. Adapun sketsa dan model tiang utama bus yang dihasilkan dari FEM diberikan pada gambar 4. 


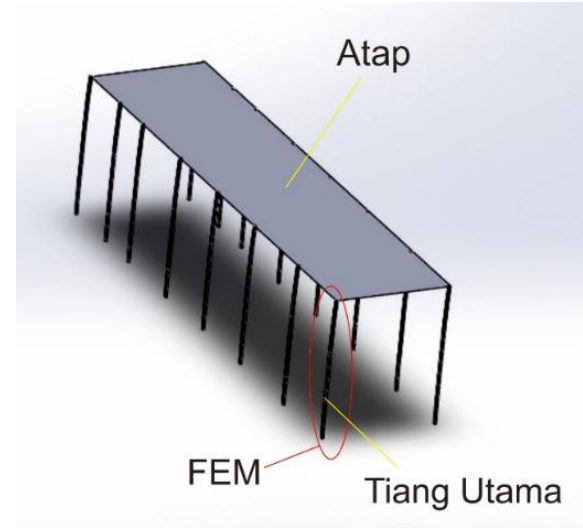

\section{Gambar 4. Model tiang utama dengan menggunakan FEM}

Diagram alir pemodelan dan analisis dengan FEM dari tiang utama pada rangka bus diberikan pada gambar 5. Pembuatan gambar model dilakukan dengan teliti berdasar data lapangan agar didapatkan hasil analisis sesuai dengan yang diharapkan. Hasil yang didapat adalah tegangan dan displacement.

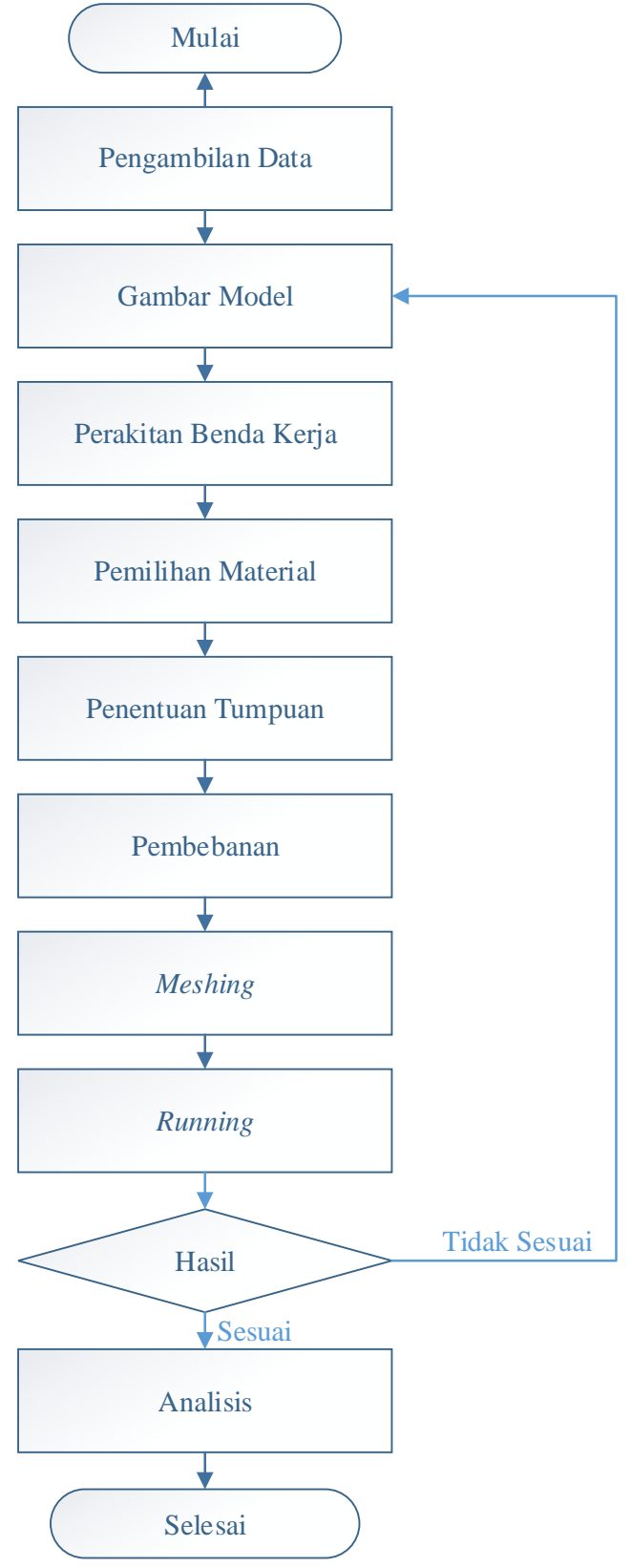

Gambar 5. Diagram alir pemodelan

Pembebanan yang diberikan pada ujung atas tiang utama sebesar 5 kali berat atap bus, sebagaimana disarankan oleh pihak karoseri. Atap bus juga memakai rangka seperti tiang utama. Berat atap bus untuk model tunggal lebih ringan dibanding model ganda. Untuk satu tiang utama model tunggal, beban yang diberikan sebesar $50 \mathrm{~N}$, sedangkan untuk satu tiang utama model ganda, beban yang diberikan sebesar 70 N. Model pembebanan yang diberikan pada tiang utama dapat dilihat pada Gambar 6. 


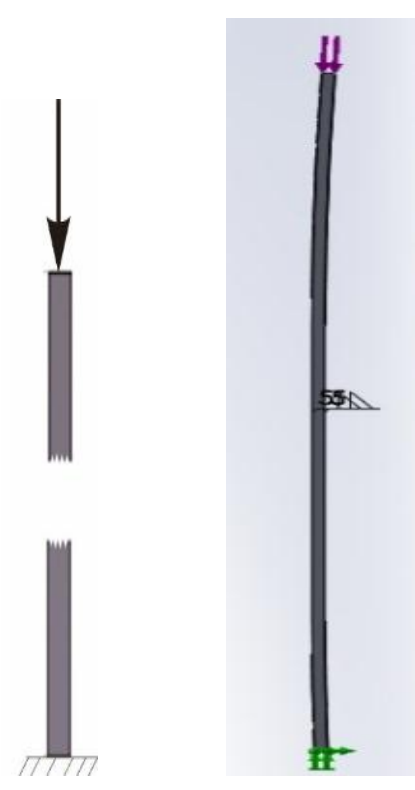

(a)

(b)

\section{Gambar 6. Pembebanan yang diberikan pada tiang utama, (a) sketsa (b) model FEM.}

Berikut ini adalah hasil meshing tiang utama yang akan di analisis. Titik constrain ditentukan sesuai dengan data lapangan, berupa tumpuan jepit dibagian bawah. Beban yang diberikan di ujung atas adalah sebesar $50 \mathrm{~N}$ untuk tiang utama tanpa pengelasan dan $70 \mathrm{~N}$ tiang utama dengan pengelasan. Tiang bus dikenai gaya sesuai dengan arah yang telah ditentukan. Meshing yang digunakan adalah standard mesh dengan jumlah nodal 20.566 dan jumlah element 10.375. Hasil dari meshing benda kerja dapat dilihat pada tabel 2 dibawah ini.

Tabel 2. Hasil meshing benda kerja

\begin{tabular}{|c|c|c|}
\hline & $\begin{array}{c}\text { Tiang Utama } \\
\text { Model Tunggal }\end{array}$ & $\begin{array}{c}\text { Tiang Utama } \\
\text { Model Ganda }\end{array}$ \\
\hline $\begin{array}{c}\text { Jumlah } \\
\text { Nodal }\end{array}$ & 67.386 & 78.031 \\
\hline $\begin{array}{c}\text { Jumlah } \\
\text { Element }\end{array}$ & 33.706 & 40.730 \\
\hline
\end{tabular}

\section{HASIL DAN PEMBAHASAN}

Berdasarkan analisis tiang utama dengan menggunakan SolidWorks, didapatkan hasil simulasi berupa tegangan dan displacement untuk tiang bus model tunggal dan model ganda. Distribusi tegangan von Mises dari tiang model tunggal diberikan pada gambar 7, sedangkan untuk tiang model ganda diberikan pada gambar 8. Gambar ditampilkan dalam mode perspektif, ujung bawah sebagai tumpuan bawah dan ujung atas sebagai tempat beban.
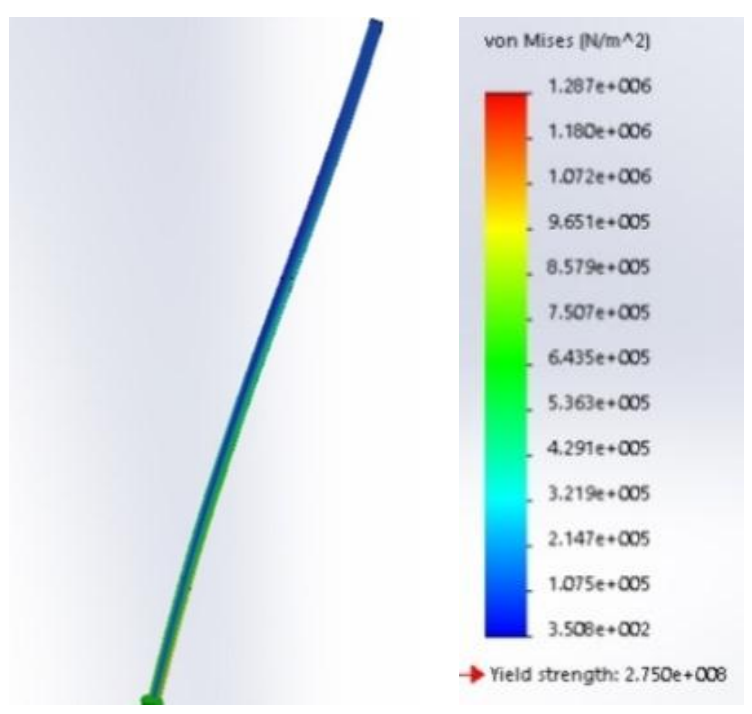

\section{Gambar 7. Hasil analisis tegangan tiang utama model tunggal}

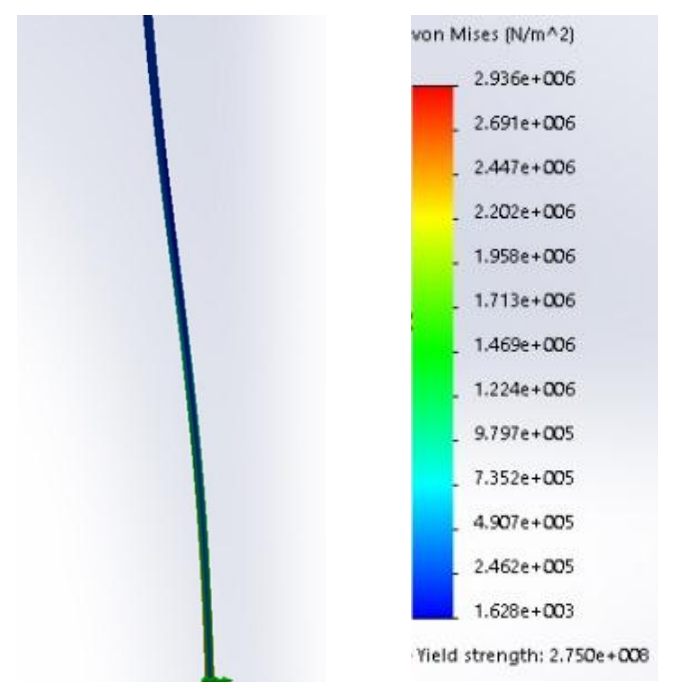

\section{Gambar 8. Hasil analisis tegangan tiang utama model ganda}

Secara umum, tegangan maksimum pada tiang model ganda lebih besar dari tiang model tunggal. Dari gambar 7, tiang utama model tunggal mempunyai tegangan sebesar $1,287 \mathrm{x}$ $10^{6} \mathrm{~N} / \mathrm{m}^{2}$ dan dari gambar 8 , tiang utama model ganda mempunyai tegangan sebesar $2,936 \times 10^{6}$ $\mathrm{N} / \mathrm{m}^{2}$. 


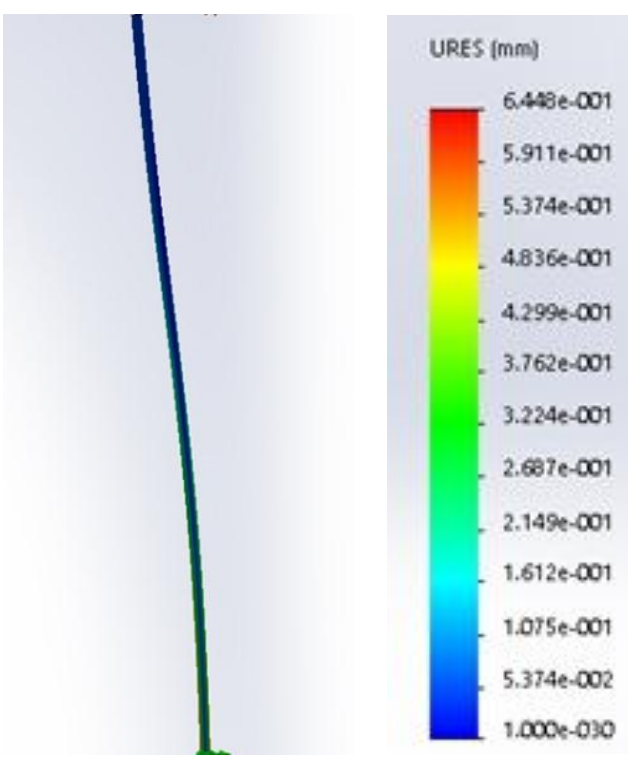

\section{Gambar 9. Hasil analisis displacement tiang utama model tunggal}

Distribusi perpindahan (displacement) dari tiang model tunggal diberikan pada gambar 9, sedangkan untuk tiang model ganda diberikan pada gambar 10 .

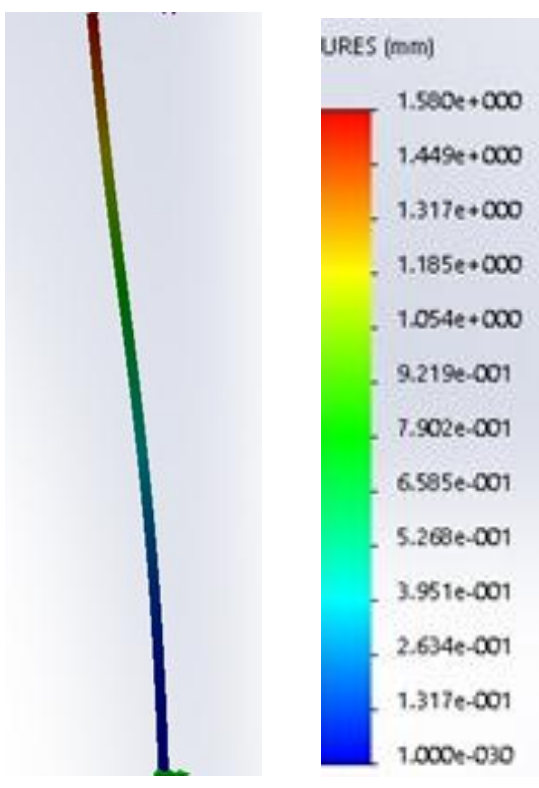

\section{Gambar 10. Hasil analisis displacement tiang utama model ganda}

Secara umum, perpindahan yang terjadi pada model ganda lebih besar dibanding yang terjadi di model tunggal. Dari gambar 9, tiang utama model tunggal mempunyai displacement sebesar $6,448 \times 10^{-1} \mathrm{~mm}$ dan dari gambar 10 , tiang utama model ganda mempunyai displacement sebesar $1,580 \mathrm{~mm}$.
Tabel 3. Perbandingan tegangan dan displacement

\begin{tabular}{|l|c|c|c|}
\hline \multirow{2}{*}{} & \multicolumn{3}{|c|}{ Parameter yang dianalisis } \\
\cline { 2 - 4 } & $\begin{array}{c}\text { Tegangan } \\
\left(\mathrm{N} / \mathrm{m}^{2}\right)\end{array}$ & $\begin{array}{c}\text { Displacement } \\
(\mathrm{mm})\end{array}$ & $\begin{array}{c}\text { Safety } \\
\text { factor }\end{array}$ \\
\hline $\begin{array}{l}\text { Model } \\
\text { Tunggal }\end{array}$ & $1,287 \times 10^{6}$ & $6,448 \times 10^{-1}$ & 213,7 \\
\hline $\begin{array}{l}\text { Model } \\
\text { Ganda }\end{array}$ & $2,936 \times 10^{6}$ & 1,580 & 93,7 \\
\hline
\end{tabular}

Secara menyeluruh perbandingan kedua analisis diatas antara tiang utama model tunggal dan tiang utama model ganda dapat dilihat pada tabel 3. Dari tabel diatas, tegangan dan displacement terbesar ada pada tiang utama model ganda yaitu berturut turut sebesar 2,936 x $10^{6} \mathrm{~N} / \mathrm{m}^{2}$ dan $1,580 \mathrm{~mm}$.

Berdasarkan hasil analisis, tiang utama model tunggal dengan tegangan $1,287 \times 10^{6}$ $\mathrm{N} / \mathrm{m}^{2}$ mempunyai nilai safety factor (SF) sebesar 213,7 dan tiang utama model ganda mempunya nilai safety factor (SF) sebesar 93,7. Berdasarkan nilai nilai safety factor (SF) tersebut, tiang utama model tunggal mempunyai tingkat keamanan lebih besar daripada tiang utama model ganda.

\section{KESIMPULAN}

Dari analisis yang telah dilakukan diatas, dapat ditarik beberapa kesimpulan sebagai berikut,

1. Simulasi FEM menunjukkan perbedaan tegangan maupun displacement pada struktur tiang utama bus model tunggal dan model ganda jika dikenai gaya $5 \mathrm{x}$ dari massa atap.

2. Tegangan dan displacement pada tiang utama model tunggal yaitu berturut turut sebesar $1,287 \times 10^{6} \mathrm{~N} / \mathrm{m}^{2}$ dan $6,448 \times 10^{-1}$ $\mathrm{mm}$. Sedangkan tegangan dan displacement pada tiang utama model ganda yaitu berturut turut sebesar $2,936 \times 10^{6} \mathrm{~N} / \mathrm{m}^{2}$ dan 1,580 $\mathrm{mm}$.

3. Bentuk rangka tiang utama yang terbaik adalah tiang utama model tunggal karena memiliki angka keamanan yang tinggi dengan tegangan dan displacement yang rendah.

\section{DAFTAR PUSTAKA}

Pratama, Bayu F., and Toni P., 2013, Analisa Frontal Impact Pada Struktur Rangka Bus Menggunakan Finite Element Method 
(FEM), Teknik Mesin Universitas Diponegoro, Semarang.

Segerlind, Larry J., 1984, Applied Finite Element Analysis, edisi Kedua, Canada: John Wiley and Sons Inc.

Smallman, Raymond E. and R.L. Bishop, 1999, Modern physical metallurgy and materials engineering, Butterworth-Heinemann.

Statistik Perhubungan, 2015, Kementerian Perhubungan

Teodorovic, Dusan and Milan Janic, 2017, Transportation Engineering : Theory, Practice and Modeling, Chapter 7, pp. 387493, Elsevier.

Timoshenko, S., 1980, Strength of Material, Edisi Kedua. New York: D. Van Nostrad Company Inc.

Volvo, 2015, Volvo Buses India, dilihat 5 februari 2018 , http://www.volvobuses.com/bus/

india/en-in/buses/Chassis/Pages/

chassis.aspx

Weck, Oliver de and Il Yong Kim, 2004, Engineering Design and Rapid Prototyping: Finite Element Method. Cambridge: Massachusetts Institute of Technology. 